\title{
Envisioning Regional Library Groups
}

\author{
Elizabeth Young Miller, Moravian College and Moravian Theological Seminary \\ Stacie Schmidt, Biola University \\ Gillian Harrison Cain, Director of Member Programs, Atla
}

\begin{abstract}
The past presidents of the Southeastern Pennsylvania Theological Library Association (SEPTLA) and the Southern California Theological Library Association (SCATLA), along with a representative from Atla, share the challenges and benefits of regional groups and how Atla can offer support. Panelists discuss ways their regional organizations can remain relevant and move forward.
\end{abstract}

\section{SOUTHEASTERN PENNSYLVANIA THEOLOGICAL LIBRARY ASSOCIATION (SEPTLA)}

From May 2018 to May 2019, I (Elizabeth Young Miller) served as the president of the Southeastern Pennsylvania Theological Library Association, also known as SEPTLA. With the election of a new president during our spring 2019 meeting, I am happily stepping into the role of past president. Before I share more details about SEPTLA, I would like to highlight some information from a March 2019 Ithaka S+R issue brief entitled "Restructuring Library Collaboration: Strategy, Membership, and Governance." ${ }^{1}$

During a special Executive Committee meeting in April, my SEPTLA colleagues and I discussed this article by Roger C. Schonfeld. The author explains that, historically, library collaborations have focused on one of the following: resource sharing, shared systems, and/or collective purchasing. ${ }^{2}$ Some of these partnerships may apply to your organizations. Certainly, some of these collaborations are relevant to SEPTLA. What seemed to resonate with the Executive Committee involved the importance of what Schonfeld refers to as trust networks-collaborative endeavors that revolve around shared priorities. ${ }^{3}$ In the last several years, SEPLTA has attempted to discern what the priorities of the organization are and how these goals can 
be realized. Certainly, assessment is important for any organization, and Schonfeld recommends a regular risk assessment process. ${ }^{4}$ The Executive Committee's discussion of this article was a form of assessment. With an upcoming election and no viable nominations, we were trying to figure out what our next steps as an organization might be. I found Schonfeld's section labeled "Directions Forward" most helpful. ${ }^{5}$ The Executive Committee wanted to honor our past and be realistic about our future. Before delving into more specific challenges and opportunities facing SEPTLA, I would like to share some background information on the organization.

SEPTLA was founded in 1964. My colleague Jim Humble, who is the current SEPTLA Archivist, shared with me that the earliest minutes from 1968 center on discussions surrounding cooperative purchasing, a focus mentioned by Schonfeld in his issue brief. ${ }^{6}$ Currently, there are seventeen institutional members of SEPTLA, representing Catholic, Eastern Orthodox, Jewish, and Protestant graduate-level, faith-based institutions. SEPTLA is composed entirely of institutional members. Individual membership is not an option at this time. SEPTLA member libraries are located between eastern Pennsylvania and central New Jersey. Collectively, our libraries hold over 2,000,000 volumes related to theology and connected disciplines. ${ }^{7}$ SEPTLA's annual dues are $\$ 75$ per institution and aid with professional development.

However, the benefits of membership extend beyond professional development to include reciprocal borrowing. With a special form and appropriate ID, faculty, staff, and students from any SEPTLA institution can directly borrow books from another SEPTLA library; this reciprocal agreement greatly expands the resources available to library users. In addition to reciprocal borrowing, SEPTLA provides valuable networking opportunities, both in person and virtually. The organization hosts both a fall and a spring meeting, and in the past has received funding from Atla to bring outside speakers for a biennial spring workshop. At the spring 2019 meeting, the past president, Myka Kennedy Stephens, offered a hands-on workshop on Slack, an online communication tool, similar in some respects to AOL Instant Messenger. SEPTLA now has channels for its interest groups and other topics of interest such as collection development. The hope is that Slack can be used to create an expertise list, providing a means to share best practices and 
build community. Slack can certainly be used for networking and to promote events and opportunities, such as the Atla scholarship. In the past, SEPTLA has awarded first-time Atla conference attendees money to attend the national conference. At our spring meeting, the organization decided to open the application to any SEPTLA librarian, with preference given to first-time attendees and presenters. In order to offer these and other benefits to our membership, SEPTLA has a well-defined leadership structure, comprised of several committees, interest groups, and specific task forces.

Both elected and appointed officers serve in leadership roles within SEPTLA. The Executive Committee comprises a secretary, treasurer, president, and past president; all of these officers are elected by the membership. With the exception of the treasurer, who serves a four-year term, each of these positions is for a one-year term, with the opportunity for re-election to a second year term, if desired. In addition to the Executive Committee, there are appointed officers who serve on the Continuing Education Committee, as well as the Communications Committee. The Continuing Education Committee oversees programming for the fall and spring meetings and consists of a chair and three additional members. The Communications Committee is composed of five members: a website manager, newsletter editor, archivist, and two at-large members. The website manager and newsletter editor serve as co-chairs of the Communications Committee.

In addition to the Executive, Continuing Education, and Communications Committees, SEPTLA has two interest groups and special task forces as needed. SEPTLA's current interest groups include Research Services and Cataloging and Metadata, both of which now have channels in SEPTLA's Slack workspace. Currently, there are no active task forces. However, in the last four years, there have been several. Task forces are created by the Executive Committee with a specific charge For example, the Future Task Force arose around the time that Gillian Harrison Cain led a SEPTLA meeting, sharing about other regional Atla groups. The Future Task Force developed a survey and facilitated several brainstorming sessions, encouraging members to share their ideas and vision for the future of SEPTLA. These discussions have been helpful for the organization. Schonfeld in his issue brief emphasizes that "[i]t can be problematic to repurpose a given trust 
network for a new purpose without carefully assessing its governance and capabilities."8 The SEPTLA leadership certainly agrees with this statement. In 2017 and 2018, I chaired the Membership Task Force, which I believe stemmed from the work of the Future Task Force. The Membership Task Force surveyed regional Atla groups, as well as other regional library groups in Pennsylvania and New Jersey, asking questions about membership criteria, dues, programming, leadership, etc. The Executive Committee has followed up on some of the recommendations of this task force. The most recent task force was the Resource Sharing Task Force, which completed its charge in the fall of 2018. The Resource Sharing Task Force examined databases that member libraries subscribe to and explored the possibility of consortial purchasing, with a special emphasis on the Digital Theological Library (DTL). Collective purchasing is nothing new, as the Ithaka $\mathrm{S}+\mathrm{R}$ issue brief highlights. ${ }^{9}$

Clearly the work of recent task forces has aided with revitalization efforts. However, I would be remiss if I did not mention the challenges individual SEPTLA libraries and SEPTLA as a regional group have faced. Nearly all libraries experience financial pressures. Budgets are shrinking, which affects personnel and collections. Being cognizant of these issues, the SEPTLA Resource Sharing Task Force was formed, and most recently there is interest in cooperative collection development. At the spring 2019 SEPTLA meeting, members asked if our bylaws should include a financial commitment to develop our individual collections and whether a collection overlap analysis using something like GreenGlass might be beneficial. Change seems to be the constant at our individual institutions, which has had a direct impact on SEPTLA operations. In an e-mail shared with the SEPTLA membership in advance of our spring 2019 meeting, Past President Myka Kennedy Stephens and I highlighted that two-thirds of our institutions have had a new library director in the last five years; this does not account for other staffing changes both inside and outside of the library. With this flux, it has been challenging to find volunteers willing to serve in leadership roles within SEPTLA and, as a result, several positions remained vacant this year. Over time, this makes for an unsustainable model. At the special Executive Committee meeting in April, the Executive Committee discussed several ways forward, including a three-year 
rotating leadership model, whereby somebody from each institution would serve first as secretary, then as president, and finally as past president. This is a model that we are still fleshing out. In addition to discussing this idea, the Executive Committee will most likely be exploring how we can do a better job reaching out to new library directors to promote the collective wisdom and benefits of SEPTLA. Networking is not only valuable for changes in leadership, but can aid the organization as several institutions undergo mergers and moves. Supporting one another and sharing words of wisdom will be helpful. Slack and the SEPTLA listserv, hosted by Atla, can aid us in these endeavors. These modes of communication also help keep members connected, which can sometimes be challenging given our geography. In the past, reaching a quorum for changes to the bylaws and constitution have been an issue. Now, however, SEPTLA is using video conferencing, such as Zoom, for business meetings, as well as workshops. SEPTLA is not a "perfect" institution. However, the members are trying to look for opportunities to address our challenges and remain relevant.

\section{SOUTHERN CALIFORNIA THEOLOGICAL LIBRARY ASSOCIA- TION (SCATLA)}

The Southern California Theological Library Association (SCATLA) was founded in 1988 with the goal of being a theological library group like SEPTLA. SCATLA currently has twenty-seven institutional members, with two tiers of membership available: full members and affiliate members. SCATLA libraries are located all over Southern California, but are predominantly located in the Los Angeles region.

The following timeline was put together via material found in the SCATLA archives and the SCATLA website:

1988: SCATLA founded by six original institutions (Azusa Pacific University, Biola University, Claremont School of Theology, Fuller Theological Seminary, The Master's Seminary, St. John's Seminary)

1989: First goal: creating a union list of periodicals

1990: Implemented free interlibrary loan for member libraries

1993: Reciprocal Borrowing program created

1999: Listserv created, almost immediately discarded 
2003-2006: Bylaws codified

2006: "No formal structural tie with ATLA" acknowledged via email

2018: Listserv attempt \#2, hosted by Atla

The Reciprocal Borrowing Program has been SCATLA's most significant project. In its original iteration, graduate students from full member libraries were interviewed by library staff to determine if they needed specific resources at another full member library. Location was not an acceptable reason to use another library. In its current iteration, graduate students and faculty from a full member library may go to any other full member library for any reason, including location.

To be a full member of SCATLA, the interested library must have graduate programs in religion or theology (any faith tradition or background), have at least 10,000 print volumes, have at least one full-time librarian, and be accredited by a Council of Higher Education Accreditation (CHEA)-recognized organization. ${ }^{10}$ Reciprocal borrowing and interlibrary loan (ILL) are available for full members of SCATLA. Affiliate membership is available for any library that does not meet the qualifications of full membership. Reciprocal borrowing and ILL are not available for affiliate member libraries. Both full and affiliate members are welcome to attend SCATLA meetings. There are currently no dues for either full or affiliate membership.

There are three levels of leadership in SCATLA: secretary, vice president, and president. Individuals are voted in at the secretary level, and then move up into a new position each year. There are three SCATLA meetings a year, and members are required to attend at least one meeting in six to keep their member status. The yearly meetings comprise two business meetings and one professional development meeting. Historically, physical attendance is required; however, SCATLA recently started experimenting with digital attendance via Zoom.

There are a number of challenges facing SCATLA. The library world has changed since 1989; prominent concerns at the time of SCATLA's founding, like union lists of periodicals, are less pressing in 2019. The requirements for full membership have also seen some recent discussion, as some libraries in Southern California that would like to become full members of SCATLA do not have a full-time librar- 
ian. The continuous turnover in leadership can sometimes lead to reduced effectiveness, as new librarians to SCATLA are frequently elected to leadership and need time to acclimate. Outdated and ineffective documentation is another challenge, as there is little documentation available beyond the bylaws. Finally, low stakes leading to apathy is another challenge facing SCATLA. Does SCATLA have a clear mission in 2019? How can SCATLA articulate its reason for existing in a way that increases member engagement? It can be difficult to make updates or changes in a lethargic environment.

Ithaka S+R's report entitled "Restructuring Library Collaboration" provides a helpful schema for understanding future growth and development in collaborative library groups. ${ }^{11}$

\section{Mission}

The SCATLA Archives currently sit in several file folders, inaccessible to anyone but their current holder. How can SCATLA members make these documents accessible to membership? Will digitization and dissemination assist SCATLA in remembering its mission?

\section{Membership}

SCATLA's website is hosted by Atla. With the Atla rebranding and new website, SCATLA's website is finally up to date. Will this allow SCATLA to attract new members?

\section{Governance}

Digital participation in the triannual meetings is now allowed, with the goal of allowing all stakeholders and members to participate in meaningful ways regardless of their physical location. Will this increase participation in governance and involvement?

\section{Funding}

SCATLA currently has no funding. Is it appropriate to charge dues? If so, how much and for what purposes?

\section{Closing}

SCATLA has served the theological library community in Southern California well for over three decades. For the latest on SCATLA, please visit: https://www.atla.com/learning-engagement/groups/ $\mathrm{rg} / \mathrm{scatla} /$. 


\section{ATLA \& REGIONAL GROUPS - AN OVERVIEW}

When I started at Atla just over four years ago, I was a little confused and intrigued by the relationship between Atla and regional groups. Unlike other national library associations that have regional chapters and affiliates that are officially related to the national organization, the regional groups that associate themselves with Atla have no formal affiliation. Over the past several years I've taken time to research and learn about the various regional groups and consider how Atla and regional groups can work together to grow and strengthen opportunities for religious studies and theological librarians to connect and learn.

In the course of this presentation I will share information about regional groups and their organizational structures; the membership models they use; projects, programs, and services offered by regional groups; and the frequency and typical agendas of regional group meetings. I will also share what current support Atla provides to regional groups and offer some thoughts and suggestions on how we could collaborate more in the future.

All the information presented has been compiled by Atla staff who reviewed the Atla website, regional group websites, and conversations with regional group leaders. This information was originally compiled in 2016 and has been updated annually, with the last updates completed in May 2019.

\section{Regional Groups \& Organizational Structures}

Currently, nineteen active regional groups across North America consider themselves to have a relationship to Atla in some way, shape, or form. There are two distinct types of groups: those that are formally organized and often incorporated at the institution level with a library council or committee, or a shared library; and regional groups that could be considered a library association, consortium, or cooperative and may or may not be incorporated.

The Northeast US has a concentration of groups reflecting the higher concentration of seminaries, colleges, and universities in that 


\section{Active \\ Regional \\ Groups (19)}

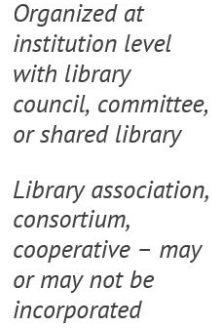

Library association, consortium, cooperative - may or may not be incorporated

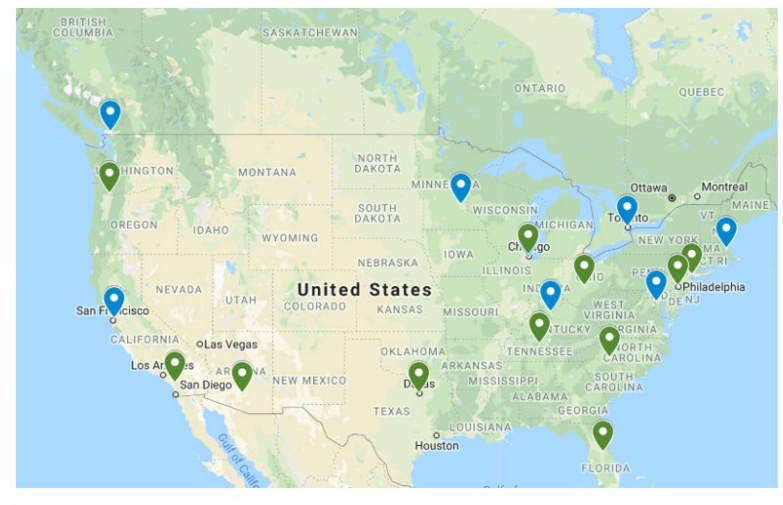

area, with other groups scattered across the US and two groups in Canada. Atla's relationships with library associations outside North America, such as BETH, ANZTLA, ForATL, and others, are better characterized as peer-to-peer.

The following eight groups are organized at the institution level:

- Associated Canadian Theological Schools of Trinity Western University (ACTS)

- Association of Chicago Theological Schools (ACTS)

- Boston Theological Institute / Boston Theological Interreligious Consortium (BTI)

- Graduate Theological Union (GTU)

- Minnesota Theological Library Association (MTLA) of Minnesota Consortium of Theological Schools (MCTS)

- Theological Education Association of Mid-America (TEAM-A)

- Toronto School of Theology Library Committee (TSTLC)

- Washington Theological Consortium Libraries (WTC)

Eleven groups are considered a library association, consortium, or cooperative:

- Carolinas Theological Library Consortium (CTLC)

- Chicago Area Theological Library Association (CATLA)

- Florida Theological Library Association (FTLA)

- New York Area Theological Library Association (NYATLA) 
- Ohio Theological Library Association (OTLA)

- Pacific Northwest Religious Studies and Theological Library Association (PNWRSTLA)

- Southeastern Pennsylvania Theological Library Association (SEPTLA)

- Southern California Theological Library Association (SCATLA)

- Southwest Area Theological Library Association (SWATLA)

- Tennessee Theological Library Association (TTLA)

- Theological Library Cooperative of Arizona (TLCA)

These groups were founded at various points over the last seventy years since Atla was founded in 1946. A large number of groups (BTI, CATLA, GTU, SEPTLA, OTLA, TTLA, NYATLA) established themselves in the 1960's and 1970's, with only four groups (ACTS of Trinity Western University, ACTS, SCATLA, SWATLA) starting in the 1980's and 1990's. The 2000's saw four new groups (CTLC, FTLA, TLCA, PNWRTSLA) founded. There has been discussion of a Rocky Mountain group starting in the future, possibly resurrecting the group that was loosely formed to host the 2015 Atla Annual Conference. Several groups not reflected in the active list were formed to host the conference and then disbanded.

\section{MEMBERS}

Atla has a hybrid membership model, both individuals and institutions or organizations may join Atla.

Individual membership categories include Individual, Student, Retired, and Emeritus and, per the Atla Bylaws, these persons must be "engaged in professional library or scholarly communications work in theological or religious fields or [have] a demonstrated, bona fide interest in the literature of religion, theological librarianship, or the purposes and work of the Association."

Institutional membership in Atla is for libraries of accredited institutions of higher education that support programs in theology and religious studies, or for libraries at non-degree granting organizations that maintain one or more significant collections of primarily theological, religious, or ecclesiastical research material. While each institutional member must appoint a member 
representative, those representatives are not individual members, and some choose to join as an individual member in order to receive those membership benefits.

Atla Affiliate membership is for businesses, organizations, publishers, vendors, ineligible, and candidate libraries that have a demonstrated record of support for theological librarianship and the purposes and work of the Association.

Several membership models are employed across the nineteen active regional groups:

- Individuals Only-One group, TTLA, has a people-only model where only individuals may join.

- Hybrid (Individuals \& Institutions)-One group also has a hybrid model where both individuals and institutions can join. However, different from Atla, their membership model specifies that permanent part-time and full-time staff at institutional members are members and that persons who are not employed at member institutions may join individually.

- Institutions/Libraries - The model followed by the remainder of groups are for institutions or libraries to be members. Some of the criteria for membership include:

- Seminaries associated with a school

- Accredited by ATS or specific regional body

- Graduate-level programs or educational institution

- Share a library or have their own library

- Full-time librarian

- Limited to, or specifically not limited to, Atla members

The number of members in regional groups varies widely. Of the seventeen groups with institutional/library membership models, there are groups with as few as four and as many as thirty-one, with the average being twelve members. The dues range across the groups as well, with the average institutional dues being 50 USD and 10 USD for individuals. Members may also make other financial contributions to the group such as hosting meetings (providing space and meals), participating in pay-your-way meals, or meeting commitments agreed to at the institution level. 


\section{PROJECTS, PROGRAMS, AND SERVICES}

While most often valued for their networking and opportunity for face-to-face connection with colleagues, regional groups may also provide projects, programs, and services for the benefit of members. Some of the offerings of regional groups include:

- Continuing education (in-person or virtual)

- ILL

- Reciprocal borrowing

- Cross-registration

- Shared reference (in-person or virtual)

- Group purchasing

- Shared storage

- Digitization/preservation/digital exhibits

- Courier

- Grants/scholarships

- Other

- Not all groups offer all these benefits, and some groups offer no benefits other than an opportunity for members to gather and share with each other.

\section{MEETINGS}

Gatherings of regional groups typically have many of the same components, however their frequency and organization differ from group to group.

Some groups only meet annually; others meet two or three times per year. The coordinating councils or committees of groups organized at the institutional level meet more often, sometimes monthly. Some groups have specific requirements for their meetings: at least one group has attendance specifications, and the bylaws of another group require them to meet at the Atla Annual Conference.

In-person is the heavily favored meeting mode for groups. However, as attendance and participation has been waning for some groups, they are beginning to experiment with virtual meetings. Typically, meetings last two to four hours, often with a meal associated. 
The agenda for regional group meetings varies and is often dependent on the frequency with which the group meets, the programs and services the group administers, where the meeting is being held, and other factors. Usually a professional development program is included in at least one meeting per year if a group meets multiple times throughout the year, and professional development is often the highlight of groups that only meet once per year. Sharing of institutional news and developments is another staple of agendas, with some groups instituting a formal institutional report process where members submit information electronically, and others taking time for a round robin of sharing from meeting attendees. If the group is formally organized, then attending to business matters and other group administration work is often included.

\section{RELATIONSHIP TO ATLA}

As stated earlier, no groups have a formal relationship with Atla. Regional groups are not affiliates or chapters of Alta. Two groups do refer to Atla specifically in their organizing document: FTLA requires institutional membership in Atla to be a member, and SWATLA's bylaws require a meeting of the group to be held at Atla Annual. Otherwise there are no formal associations between the organizations, and some groups specifically have language stating you do not have to be a member of Atla to participate. Consequently, not all members of regional groups are members of Atla. And not all members of Atla are aware of the regional groups in their area.

That said, Atla has a long history of working with regional groups. Currently, Atla supports regional groups by:

- Promoting the organization and its activities in the Atla Newsletter, whether that be announcements of upcoming meetings, reports of meetings, or information about current group projects.

- Providing funding for programming at a regional meeting. The Professional Development Committee (PDC) offers funds to assist regional groups and has a list of pre-packaged workshops (leaders and content identified) that a group can select from to have at their meeting, funded by Atla. 
- Providing an informational website for a regional group. Atla selected and implemented a new website technology and will be implementing a new communities platform that will allow regional groups to have much more control over editing the content on the group's page-more information to come soon.

- Providing a discussion list for the group.

Atla sees a great opportunity to collaborate closely with regional groups to strengthen both of our organizations. Since our memberships are not the same, obviously there is potential for membership growth by both Atla and regional groups by promoting each other's organizations and benefits. Attending Atla Annual is not practical or possible for all members, so working with regional groups to offer programming locally would benefit members of both organizations. Additional ways that regional groups and Atla could collaborate include:

- Additional technology support - virtual meetings, project software

- Additional programming support - pre-packaged programming

- Financial relationship

- Communications

- Member recruitment and retention

- Leadership development

- Regionalized member projects and programs

- Handling the "business" aspects of a group

Atla welcomes an active discussion with leaders of regional groups to explore what working together will look like in the future. We welcome thoughts and comments from members of both organizations to help us shape a better set of benefits and opportunities for all of you. 


\section{ENDNOTES}

1 Roger C. Schonfeld, "Restructuring Library Collaboration:

Strategy, Membership, Governance,” Ithaka S+R, last modified 6 March 2019, https://doi.org/10.18665/sr.311147.

2 Schonfeld, "Restructuring Library Collaboration," 3.

3 Schonfeld, "Restructuring Library Collaboration," 6.

4 Schonfeld, "Restructuring Library Collaboration, 16.

5 Schonfeld, "Restructuring Library Collaboration, 16-17.

6 Schonfeld, "Restructuring Library Collaboration, 5.

7 "Southeastern Pennsylvania Theological Library Association," accessed May 23, 2019, https://septla.org/.

8 Schonfeld, "Restructuring Library Collaboration," 12.

9 Schonfeld, "Restructuring Library Collaboration," 5.

10 Southern California Theological Library Association, "SCATLA Bylaws,” https://www.atla.com/wp-content/uploads/2019/03/ SCATLA-Bylaws.pdf.

11 Schonfeld, "Restructuring Library Collaboration." 